\title{
Surface-Observed and Satellite-Retrieved Cloudiness Compared for the 1983 ISCCP Special Study Area in Europe
}

\author{
A. Henderson-Sellers, ${ }^{1}$ G. Sèze,$^{2}$ F. Drake, ${ }^{1}$ and M. Desbois ${ }^{2}$
}

\begin{abstract}
A comparison has been undertaken between surface-observed total low-and high-cloud amount and retrievals from METEOSAT radiance data made using the cluster technique of Desbois $e t$ al. (1982). The aim of the study was to establish whether surface-observed cloud information could be usefully exploited to beneft satellite-based cloud retrievals. Observations from 124 surface stations at 1200 UT for the 20-day period from July 22 to Auguet 10, 1983, were compared with retrievals made from METEOSAT radiances measured at 1130 UT. The comparisons for total and low-cloud amount are made for France and southern Britain. The high-cloud amount comparison was limited to 34 stations in southern Britain. The location and time period were selected to coincide with one of the regions designated for special study in the International Satellite Cloud Glimatology Project (ISCCP) (Schiffer, 1982). For total cloud amount, 29\% of the retrievals were fully in agreement with the ourface observations and $64 \%$ of differences were within \pm 1 okta $( \pm 1$ eighth of sky cover). In the case of layer cloud amounts, $64 \%$ of the low-cloud amount differences and $50 \%$ of the high-cloud amount differences were within \pm 1 okta, although many of these successes (71\% in the low-cloud amount) were for cases of totally clear or totally cloudy skies. Surface observations, which offer the only source of accurate low-cloud amount evaluation in any multilayered situation, were found to identify thin cirrus which was not detected by the satellite retrieval and to detect small gaps in cloud decks and small clouds missed by the satellite retrieval. In addition, cloud retrievals in coastal locations seemed to be more successfully accomplished by surface observers than by the satellite retrieval algorithm used here, which does not take into account land-sea partition.
\end{abstract}

\section{INTRODUCTION}

It has been widely recognized that the radiative properties of clouds need to be better known and understood [Global Atmospheric Research Program (GARP), 1978]. To this end a new global cloud climatology is at present being compiled under the auspices of the International Satellite Cloud Climatology Project (ISCCP) [Schiffer, 1982; Schiffer and Rossow, 1983, 1985]. This will be a 5-year archive, beginning in 1983, and is being compiled from satellite data. One of the stated objectives of the research component of ISCCP is "investigation of methods to infer additional cloud properties from satellite observations." [Rossow et al., 1985, p. 901]. In order to achieve such an objective it is first essential to establish which cloud properties are readily and successfully derivable from satellite data and which are less accessible. One approach is to compare results from a range of different cloud retrieval algorithms. Such a comparison (described by Rossow et al., [1985]) formed the basis for the construction of the ISCCP algorithm. The fact that cloud fields are three-dimensional suggests an alternative, complementary approach: comparison of surface (bottom-up) and satellite (top-down) cloud retrievals. As part of the research component of the ISCCP, a joint venture by United Kingdom and French scientists has focused on a comparison of surface observations and satellite retrievals of clouds.

It must be recognized that the comparison described here is not intended to be a validation exercise. Indeed the term "validation" is hard to understand in the context of a mul-

\footnotetext{
${ }^{1}$ Department of Geography, University of Liverpool, Liverpool, England.

${ }^{2}$ Laboratoire de Météorologie Dynamique, Centre National de la Recherche Scientifique, Palaiseau, France.

Copyright 1987 by the American Geophysical Union.

Paper number 6D0383.

0148-0227/87/006D-0383\$05.00
}

tilayered, overlapping, and dynamic cloud scene. In order to capture the fullest description of clouds, the best possible approach might be the strategy adopted by the U.S. Air Force, which includes as much information as possible: surface observations, satellite retrievals and aircraft reports [Fye, 1978]. On the other hand, this practice leads inevitably to heterogeneity [e.g., Hughes and HendersonSellers, 1985]. Another way to help resolve the dilemmas of insufficient data and ambiguous satellite retrievals is to exploit additional information or retrieval methods only where they can improve the cloud characterization substantially. One example of this is to improve cloud cover and type evaluation using statistical retrievals for selected scenes [Rossow et al., 1985]. In this paper, another question is examined: whether surface observations of clouds can be exploited to resolve ambiguities in satellite retrievals and to add lowerlayer information unobtainable from satellites.

\section{Data Sources and Methods of Comparison}

\subsection{Location and Timing}

The location (France and southern Britain) and the time period studied (July 22 to August 10, 1983) were selected to coincide with one of the special study regions identified by ISCCP. Meteorologically, the 20-day period offers a range of conditions typical of this region in the summertime. There was an outbreak of Saharan dust from north Africa which spread over the Mediterranean Sea early in the period, while depression systems crossed the northern part of the region. Beginning around July 28 , an anticyclone drifted in from the west to become established over the region, and it dominated the synoptic conditions for the rest of the period. The last few days in July saw very high temperatures over most of Europe. Cloud types were varied, including advected fog; cumulonimbus (especially over southern France), frontal cloud, and isolated cirrus.

The method of investigation was twofold: a straightforward comparison of surface and satellite cloud retrievals pre- 
ceded a detailed analysis of specific cases and features. Sections 2 and 3 describe the data and preliminary results. In section 4 these results are reviewed in the context of earlier work, and proposals are made in section 5 .

\subsection{Surface Observations}

Surface observations were supplied by the United Kingdom Meteorological Office and the Direction de la Météorolo- gie de France. The observation stations used were those making round-the-clock observations (i.e., every hour in the United Kingdom and 3-hourly in France). These stations were selected because it was believed that the observational data would be more likely to be consistent from such sources. Both the United Kingdom and France use the okta code (eighths of sky covered) for reporting cloud amount. However, in the United Kingdom, the number 9 is used to indicate sky obscured, whereas in France, the number -9 is used to indicate that the sky is obscured or there is a datum missing, and the number -1 indicates a data problem. An attempt was made to exclude stations in which these codes appeared; in the analyzed data they appear on only five separate occasions. Altogether, 124 stations were used: 34 stations scattered over England and Wales and 90 located in France (see Table 1).

For the French stations, only total and low-cloud amounts were supplied, which confined the study of high-cloud amount to the United Kingdom only. The amount of high cloud was not supplied as such. Instead, information on the three lowest cloud layers is supplied. The layers are reported in accordance with the following criteria: (1) the lowest individual layer of any amount; (2) the next higher individual layer with an amount which is greater than or equal to 3 oktas; (3) the next higher individual layer with an amount which is greater than or equal to 5 oktas; (4) if cumulonimbus is observed but not reported in the above categories, it is reported as a separate fourth category. Thus high cloud can fall in any or none of the first three categories, depending upon the synoptic conditions. In order to obtain the high-cloud amount, any observations of a cloud at an altitude of $6 \mathrm{~km}$ or higher was considered to be a high cloud [Her Majesty's Stationary Office (HMSO), 1969]. The cloud data used in the comparison are all midday (1200 UT) okta cloud amounts for the period July 22 to August 10, 1983.

\subsection{Satellite Observations}

The cloud amounts were derived from METEOSAT images taken at 1130 UT each day. As the primary objective was to establish whether surface observations could be used in selected situations to complement satellite data, only one retrieval algorithm was used. The chosen algorithm, which uses a clustering technique, is described by Desbois and Sèze [1984] and Sèze and Desbois [1986] and will only be outlined here.

The method combines spectral, spatial, and temporal information. Each pixel of a chosen image segment is represented by four parameters: two spectral ones (visible and infrared values) and two spatial ones (local variances computed from the eight neighbors in the visible and infrared images). First a four-dimensional cumulative histogram is built up for each segment for 10 of the 20 days. The clustering technique permits partitioning of this histogram, the result being a separation of the histogram into classes representative of surface or cloud types, defined by their center of gravity and variances. Finally, each pixel of each of the 20 images is projected on the four-dimensional histogram and is attributed to the class to which it is the nearest. The use of variances allows separation of clouds which have similar spectral characteristics. Although classes with semitransparent clouds or partial coverage of the pixels can be separated by the algorithm, pixels belonging to these classes have been considered as completely cloud covered. This is an important feature which has to be remembered in the following comparisons.

The area studied here was split into five regions (Figure 1). Although the regions overlap, each station was assigned to a particular region, as shown in Figure 1. The latitudes and longitudes of the corners of the regions are given in Table 2. The regions are larger in longitude than latitude, as the surface and atmospheric properties were thought to vary more with latitude than with longitude. There were five learning sets: one for each region.

\subsection{Selection of the Comparison Areas}

It was decided that an area $100 \mathrm{~km}$ by $100 \mathrm{~km}$ was the most useful for comparison purposes. Selection of this size was prompted by the identification by Barrett and Grant [1979] of the theoretical maximum radius of vision of a surface observer as $50 \mathrm{~km}$ and following detailed consideration of a range of surface observations [e.g., Greenwood, 1985]. To obtain the cloud amount in an area centered on each surface station, all pixels within a box $100 \mathrm{~km}$ by $100 \mathrm{~km}$ (about 15 by 19 pixels) were attributed to one of the classes in the learning set for the appropriate region. Thus the percentage coverage of each class (cloud type) can be found, and the total cloud amount can be calculated. The percentage to okta conversion used was

okta value $=$ integer value of

$$
\left[\left(\text { percentage } \times \frac{8}{100}\right)+0.5\right]
$$

\section{Regults of Initial Comparison}

\subsection{Region-Wide Comparisons}

As a preliminary exercise, scattergraphs of numbers of okta cloud retrievals made from the two platforms, surface and satellite, are shown in Figure 2. The total cloud distribution (Figure 2a) indicates the strongly bimodal nature of the retrievals. Both satellite and surface observations are more likely to be $\geq 6$ oktas or $\leq 1$ okta than between 2 and 5 oktas. For the larger cloud amounts there is a clear tendency for the satellite retrieval to be greater than the surface observations by between 1 and 2 oktas. However, this tendency is much less in the case of almost clear skies. In the case of low-cloud retrievals (Figure $2 b$ ) the bimodal feature remains, although it is very much weaker, mostly because there were very few occasions on which there were complete low-level overcasts. The high-cloud distribution (Figure 2c) contains very many fewer observations, as data are available only for southern Britain. The results are more noisy, but they show very characteristic features: surface observations of zero oktas may correspond to a wide range of high-cloud coverage by the satellite, from zero to 8 oktas. The values are also rather scattered for the nonzero values of ground observations, with a general tendency to an overestimation by the surface observer. 
TABLE 1. Surface Stations Used With Latitude, Longitude, and the Region in Which Each Occurs

\begin{tabular}{|c|c|c|c|c|}
\hline \multirow{2}{*}{ Station } & \multirow{2}{*}{\multicolumn{2}{|c|}{ Number Region }} & \multicolumn{2}{|c|}{ Latitude Longitude } \\
\hline & & & $\mathbf{N}^{0}$ & $\mathbf{E}^{\circ}$ \\
\hline Cottishall & 1 & 5 & 52.77 & 1.35 \\
\hline Hemsby & 2 & 5 & 52.68 & 1.68 \\
\hline Honnington & 3 & 5 & 52.33 & 0.77 \\
\hline Wattisham & 4 & 5 & 52.12 & 0.97 \\
\hline Wyton & 5 & 5 & $\mathbf{5 2 . 5 2}$ & -0.12 \\
\hline Bedford & 6 & 5 & 52.22 & -0.48 \\
\hline Stansted & 7 & $\mathbf{b}$ & 51.88 & 0.22 \\
\hline Elmdon & 8 & 5 & 52.45 & -1.75 \\
\hline Brice Norton & 9 & 5 & 51.75 & -1.58 \\
\hline Shawbury & 10 & 5 & 52.80 & -2.67 \\
\hline Bristol W.C. & 11 & 5 & 51.45 & -2.60 \\
\hline London W.C. & 12 & 5 & 51.52 & -0.12 \\
\hline Heathrow & 13 & 5 & 51.48 & -0.45 \\
\hline Gatwick & 14 & 5 & 51.15 & -0.18 \\
\hline Manston & 15 & $\mathbf{5}$ & 51.35 & 1.35 \\
\hline Herstmonceaux & 16 & $\mathbf{5}$ & 50.87 & 0.33 \\
\hline Hurn & 17 & 5 & 50.78 & -1.83 \\
\hline Southempton W.C. & 18 & $\mathbf{5}$ & 50.90 & -1.40 \\
\hline St. Catherines Point & 18 & 5 & 50.58 & -1.28 \\
\hline Lyneham & 20 & $\mathbf{5}$ & $\mathbf{5 1 . 5 0}$ & -1.98 \\
\hline Boscombe Down & 21 & $\mathbf{5}$ & 51.17 & -1.75 \\
\hline Aberporth & 22 & $\mathbf{5}$ & 52.13 & -4.57 \\
\hline Brawdy & 23 & 5 & 51.87 & -5.13 \\
\hline Mumbles Head & 24 & 5 & $\mathbf{5 1 . 5 7}$ & -3.98 \\
\hline Rhoose & 25 & $\mathbf{5}$ & 51.40 & -3.35 \\
\hline Cardiff W.C. & 26 & 5 & 51.48 & -3.17 \\
\hline Yeovilton & 27 & $\mathbf{5}$ & 51.00 & -2.63 \\
\hline Portland Bill & 28 & 5 & 50.52 & -2.45 \\
\hline Mount Batten & 29 & 5 & 50.35 & -4.12 \\
\hline Exeter & 30 & $\mathbf{5}$ & 50.73 & -3.42 \\
\hline St. Mawgan & 31 & 5 & 50.43 & $-\mathbf{5 . 0 0}$ \\
\hline Jersey Airport & 32 & 3 & 49.20 & -2.20 \\
\hline Gurnsey Airport & 33 & 3 & 49.43 & -2.60 \\
\hline Marham & 34 & 5 & 52.65 & 0.57 \\
\hline Cap de la Hague & $\mathbf{3 5}$ & 5 & 49.72 & -1.93 \\
\hline Pointe du Roc & 36 & 3 & 48.83 & -1.62 \\
\hline Pointe de Grouin & 37 & 3 & 48.72 & -1.85 \\
\hline Ile de Brehat & 38 & 3 & 48.85 & $-\mathbf{3 . 0 0}$ \\
\hline Ile de Batz & 39 & 3 & 48.75 & -4.02 \\
\hline Pointe du Raz & 40 & 3 & 48.03 & -4.73 \\
\hline Pointe de & 41 & 3 & 47.80 & -4.37 \\
\hline Penmarch & & & & \\
\hline He de Groix & 42 & 3 & 47.65 & $-\mathbf{3 . 5 0}$ \\
\hline Belle Ile Ole Tault & 43 & 3 & 47.30 & -3.22 \\
\hline Ile d'yeu St. Saveur & 44 & 3 & 46.70 & -2.33 \\
\hline Cap Bear & 45 & 1 & 42.52 & $\mathbf{3 . 1 3}$ \\
\hline Sete & 46 & 1 & 43.40 & 3.68 \\
\hline Ile Porquerolles & 47 & 1 & 43.00 & 6.23 \\
\hline Cap Ferrat & 48 & $\mathbf{1}$ & 43.68 & $\mathbf{7 . 3 3}$ \\
\hline Cap Pomegues & 49 & 1 & 43.27 & 5.30 \\
\hline Bec de l'Aigle & 50 & 1 & 43.18 & 5.58 \\
\hline Cap Camarat & 51 & 1 & 43.20 & 6.68 \\
\hline Cap Couronne & 52 & 1 & 43.33 & 5.05 \\
\hline Cap Cepet & 53 & 1 & 43.08 & 5.93 \\
\hline Boulogne Sur Mer & 54 & 5 & 50.73 & 1.60 \\
\hline Dieppe & $\mathbf{5 5}$ & 5 & 49.93 & 1.10 \\
\hline Brest Tour Cesar & 56 & $\mathbf{3}$ & 48.38 & -4.48 \\
\hline Bordeaux & 57 & 2 & 44.83 & -0.70 \\
\hline Clermont Ferrand & 58 & 2 & 45.75 & $\mathbf{3 . 1 7}$ \\
\hline Dijon & 59 & 4 & 47.27 & 5.08 \\
\hline Limoges Bellgarde & 60 & 2 & 45.87 & 1.18 \\
\hline Lyon Bron & 61 & 2 & 45.72 & 4.95 \\
\hline Nimes-Couberssac & 62 & 1 & 43.75 & 4.40 \\
\hline Agen & 63 & 2 & 44.18 & 0.60 \\
\hline Perpignon & 64 & $\mathbf{1}$ & 42.73 & 2.87 \\
\hline Alencon & 65 & 4 & 48.45 & 0.10 \\
\hline Rennes & 66 & 3 & 48.07 & -1.72 \\
\hline
\end{tabular}

TABLE 1. (continued)

\begin{tabular}{|c|c|c|c|c|}
\hline \multirow[b]{2}{*}{ Station } & \multirow{2}{*}{\multicolumn{2}{|c|}{ Number Region }} & \multicolumn{2}{|c|}{ Latitude Longitude } \\
\hline & & & $\mathbf{N}^{\circ}$ & $\mathbf{E}^{\circ}$ \\
\hline Brest Guipavas & 67 & 3 & 48.45 & -4.42 \\
\hline Villecoublay & 68 & 4 & 48.77 & 2.20 \\
\hline Nantes & 69 & 3 & 47.17 & -1.60 \\
\hline Marignane & 70 & 1 & 43.45 & 5.22 \\
\hline Montelimar & 71 & 1 & 44.58 & 4.73 \\
\hline Abbeville & 72 & 5 & 50.13 & 1.83 \\
\hline Langres & 73 & 4 & 47.83 & 5.32 \\
\hline Antibes La Garoupe & 74 & 1 & 43.57 & 7.13 \\
\hline Avord & 75 & 4 & 47.05 & 2.65 \\
\hline Orlean: & 76 & 4 & 47.98 & 1.75 \\
\hline Le Puy Chadrac & 77 & 1 & 45.05 & 3.90 \\
\hline Chateaudin & 78 & 4 & 48.05 & 1.38 \\
\hline latres & 79 & 1 & 43.52 & 4.93 \\
\hline Angers & 80 & 4 & 47.50 & -0.57 \\
\hline Trappes & 81 & 4 & 48.77 & 2.02 \\
\hline Toulon & 82 & 1 & 43.10 & 5.93 \\
\hline Salon-de-Provence & 83 & 1 & 43.60 & 6.10 \\
\hline Auxerre & 84 & 4 & 47.80 & 3.65 \\
\hline Les Sauvages Tarare & 85 & 2 & 45.93 & 4.38 \\
\hline Saint Raphael & 86 & 1 & 43.42 & 6.75 \\
\hline Macon & 87 & 2 & 46.30 & 4.80 \\
\hline Millau & 88 & 1 & 44.12 & 3.02 \\
\hline Toul Posieres & 89 & 4 & 48.78 & 5.98 \\
\hline Poitiers & 90 & 4 & 46.58 & 0.32 \\
\hline Bourg St. Maurice & 91 & 2 & 45.62 & 6.77 \\
\hline Cognac & 92 & 2 & 45.67 & -0.32 \\
\hline $\begin{array}{l}\text { Grenoble } \\
\text { St. Geoirs }\end{array}$ & 93 & 2 & 45.37 & $\mathbf{5 . 3 3}$ \\
\hline Gourdon & 94 & 2 & 44.75 & 1.40 \\
\hline Montpellier & 95 & $\mathbf{1}$ & 43.58 & 3.97 \\
\hline Mont de Marsan & 96 & 2 & 43.92 & -0.50 \\
\hline Mont St. Vincent & 97 & 4 & 46.65 & 4.43 \\
\hline Nice & 98 & 1 & 43.65 & 7.20 \\
\hline Vichy & 99 & 2 & 46.17 & 3.40 \\
\hline Saint Etienne & $\mathbf{A}$ & 2 & 45.53 & 4.30 \\
\hline Paris Orly & $\mathbf{B}$ & 4 & 48.73 & 2.40 \\
\hline Embrun & $\mathbf{C}$ & 1 & 44.57 & 6.50 \\
\hline Luc en Provence & D & 1 & 43.38 & 6.38 \\
\hline Canne: & $\mathbf{E}$ & 1 & 43.55 & 6.95 \\
\hline Dinard & $\mathbf{F}$ & 3 & 48.58 & -2.07 \\
\hline Le Touquet & $\mathbf{G}$ & 5 & 50.52 & 1.62 \\
\hline $\begin{array}{l}\text { Lorient Lann } \\
\text { Bihoue }\end{array}$ & $\mathbf{H}$ & 3 & 47.77 & -3.45 \\
\hline Orange & $\mathbf{I}$ & 1 & 44.13 & 4.83 \\
\hline Saint Auban & $\mathbf{J}$ & 1 & 44.07 & 6.00 \\
\hline Landivisiau & $\mathbf{K}$ & 3 & 48.52 & -4.15 \\
\hline Rostrenen & $\mathbf{L}$ & 3 & 48.23 & -3.33 \\
\hline Saint Dixier & $\mathbf{M}$ & 4 & 48.63 & 4.90 \\
\hline $\begin{array}{l}\text { Chambray aixles } \\
\text { Bains }\end{array}$ & $\mathbf{N}$ & 2 & 45.65 & 5.88 \\
\hline Parais Montsouris & $\mathbf{O}$ & 4 & 48.82 & 2.33 \\
\hline $\begin{array}{l}\text { Cherbourg } \\
\text { Maupertus }\end{array}$ & $\mathbf{P}$ & 5 & 49.65 & -1.47 \\
\hline Nancy Ochey & $\mathbf{Q}$ & 4 & 48.58 & 5.97 \\
\hline Carpentras & $\mathbf{R}$ & 1 & 44.08 & 5.05 \\
\hline Hyeres BAN & $\mathbf{S}$ & 1 & 43.10 & 6.15 \\
\hline Hyeres cem & $\mathbf{T}$ & 1 & 43.03 & 6.47 \\
\hline Levant & & & & \\
\hline Lyon Satolas & $\mathbf{U}$ & 2 & 45.73 & 5.08 \\
\hline $\begin{array}{l}\text { Toure St. } \\
\text { Symphorien }\end{array}$ & $\mathbf{V}$ & 4 & 47.45 & 0.72 \\
\hline $\begin{array}{l}\text { Apt. Saint } \\
\text { Christol }\end{array}$ & $\mathbf{W}$ & 1 & 44.05 & 5.48 \\
\hline Nimes Garons & $\mathbf{X}$ & 1 & 43.75 & 4.42 \\
\hline Captieux & $\mathbf{Y}$ & 2 & 44.18 & -0.28 \\
\hline
\end{tabular}

Letters have been used to identify stations with numbers greater than 99 . 


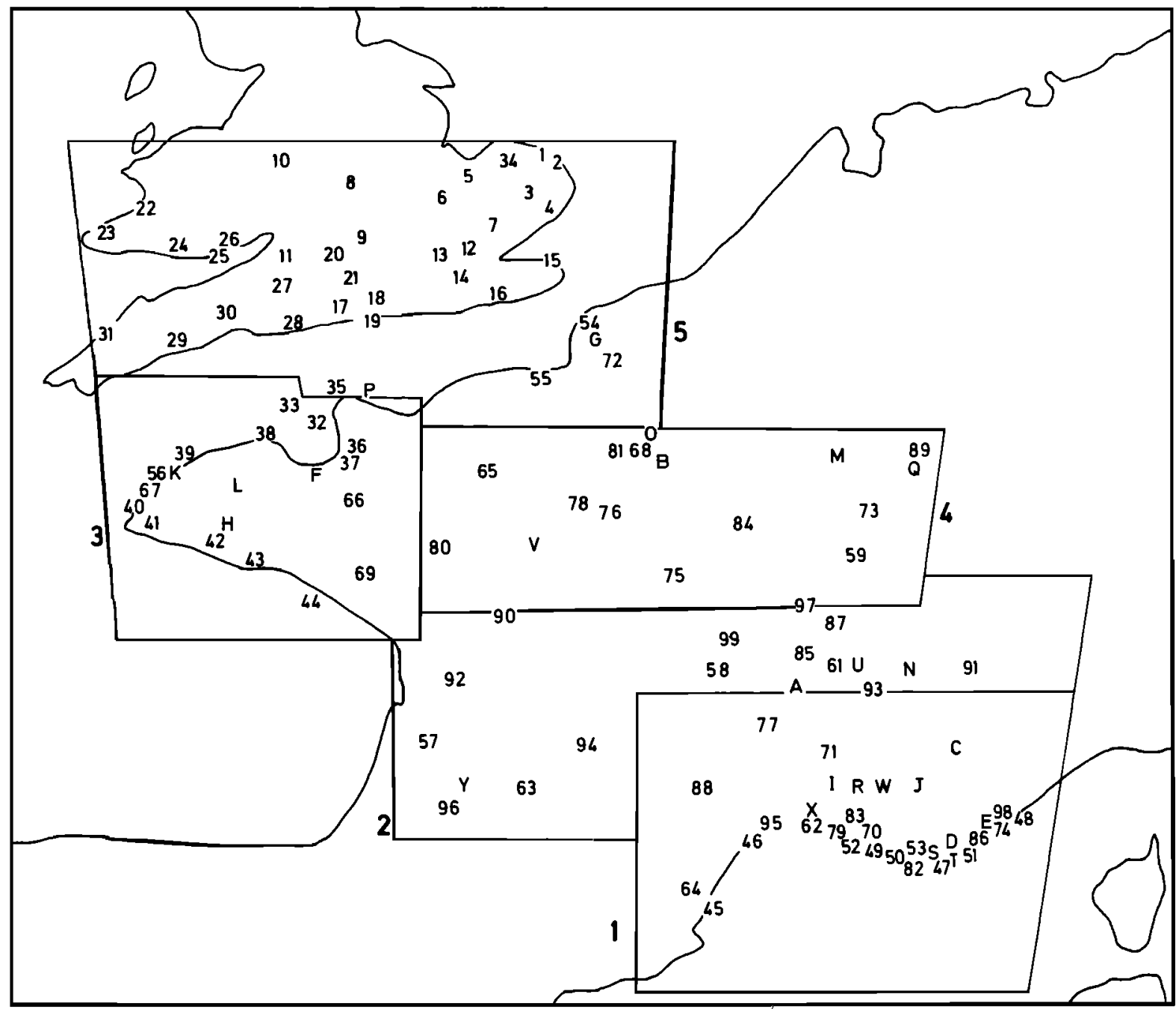

Fig. 1. Map of northwest Europe, showing the five regions and distribution of the 124 surface stations which are identified by the numbers and letters listed in Table 1 .

The okta differences between satellite and surface observations at all locations and all times have been cumulated into the frequency distributions shown in Figures $3 a$ and 4a. The terminology adopted here is that a positive cloud amount difference is an apparent surface observer overestimate and a negative cloud amount difference a satellite overestimate. These differences, of course, could be considered to be a satellite underestimate and a surface observer underestimate, respectively. However, in this study they will initially be described in terms of overestimation. A zero represents an exact agreement between the surface-observed and satellite-retrieved cloud amount. Overall, for the 124 stations over the 20 days, the most frequent okta difference is zero (Table 3). For total cloud, $28 \%$ of the differences are zero and $64 \%$ of them lie within \pm 1 okta. For low cloud, $32 \%$ of the differences are zero and $64 \%$ lie within \pm 1 okta. These results appear fairly positive, but many of these cases of good agreement are for totally clear or totally cloudy skies. In the total cloud amount case, $55 \%$ of the zero okta differences are due to agreement in totally clear or totally cloudy situations. These conditions give rise to $71 \%$ of the complete agreements in the case of low cloud. Additionally, in the total cloud amount frequency distribution (Figure $3 a)$, there-is a tendency for the satellite to overestimate, by approximately 1 okta. The low-cloud amount distribu-
TABLE 2. The Latitudes and Longitudes of the Corners of the Five Regions Shown in Figure 1

\begin{tabular}{ccc}
\hline Region & $\begin{array}{c}\text { Letitude } \\
\mathbf{N}^{\circ}\end{array}$ & $\begin{array}{c}\text { Longitude } \\
\mathbf{E}^{\circ}\end{array}$ \\
\hline 1 & 39.13 & 7.45 \\
& 39.11 & 2.08 \\
& 45.49 & 2.33 \\
2 & 45.57 & 8.36 \\
& 43.50 & 8.09 \\
& 43.42 & -1.16 \\
3 & 47.07 & -1.25 \\
& 47.17 & 8.71 \\
& 46.19 & -0.73 \\
& 46.22 & -4.95 \\
4 & 49.96 & -5.37 \\
& 49.92 & -0.79 \\
& 46.24 & 6.16 \\
& 46.19 & -1.23 \\
5 & 49.12 & -1.31 \\
& 49.13 & 6.56 \\
& 49.13 & 2.52 \\
& 49.16 & -5.27 \\
& 53.29 & -5.83 \\
& 53.24 & 2.78 \\
\hline
\end{tabular}




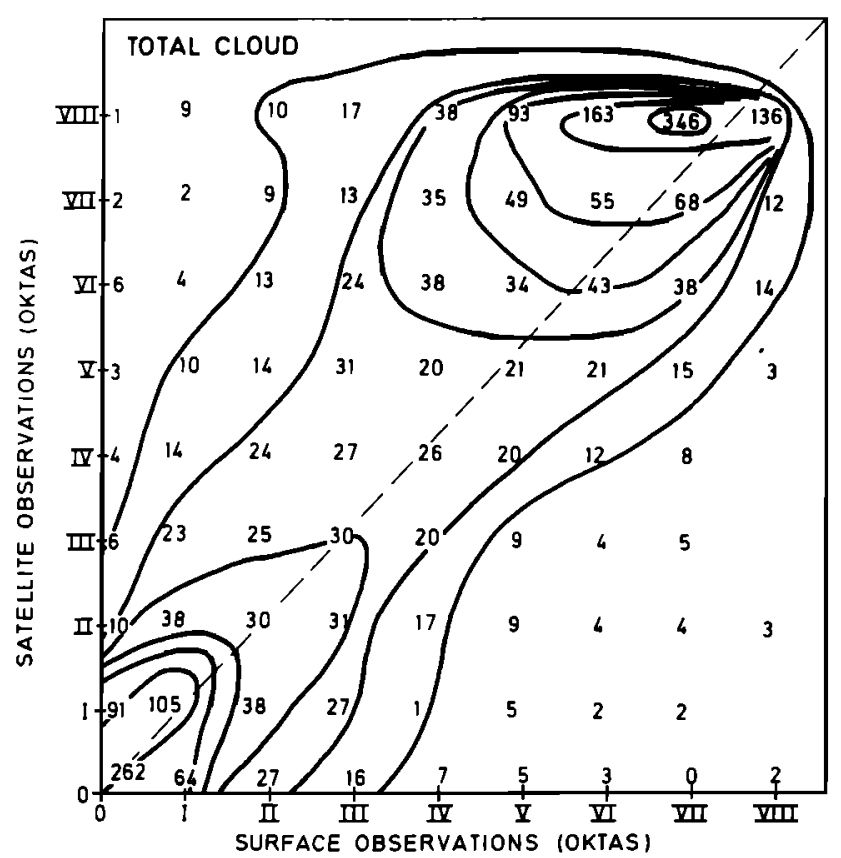

Fig. 2a. Scattergraph of total cloud amount retrievale in okta cloud amounts for surface observers and from satellite retrievals. All data for the whole period are shown.

tion (Figure 4a) shows that there is the opposite tendency, namely, for the surface observer to overestimate. These tendencies can be seen more clearly when the totally clear and totally cloudy skies agreements have been removed (Figures $3 b$ and $4 b$ ). The high-cloud frequency diagram (Figure 5a) only applies to the 34 British sations over the 20 days. Apparently $35 \%$ of the differences are zero and $50 \%$ are within \pm 1 okta. However, totally clear and totally cloudy skies are found to account for $95 \%$ of the frequency of zero differences (Figure 5b).

\subsection{Point-Specific Comparisons}

The numerical difference between the surface-observed cloud amount and the satellite-retrieved cloud amount for

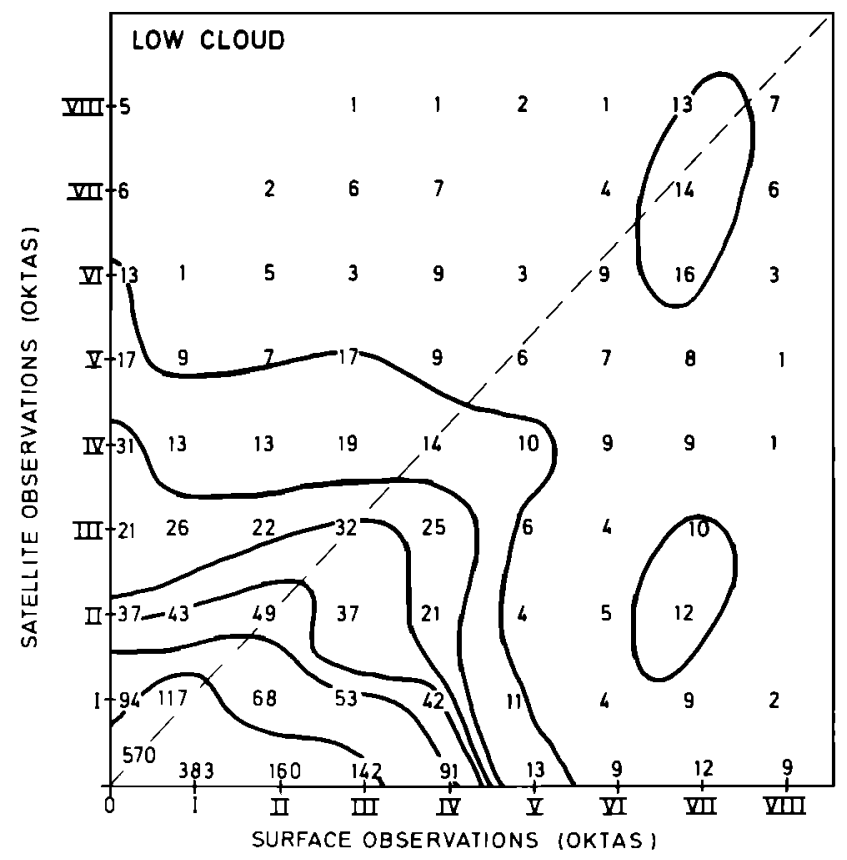

Fig. 2b. As for Figure 2a, but for low cloud.

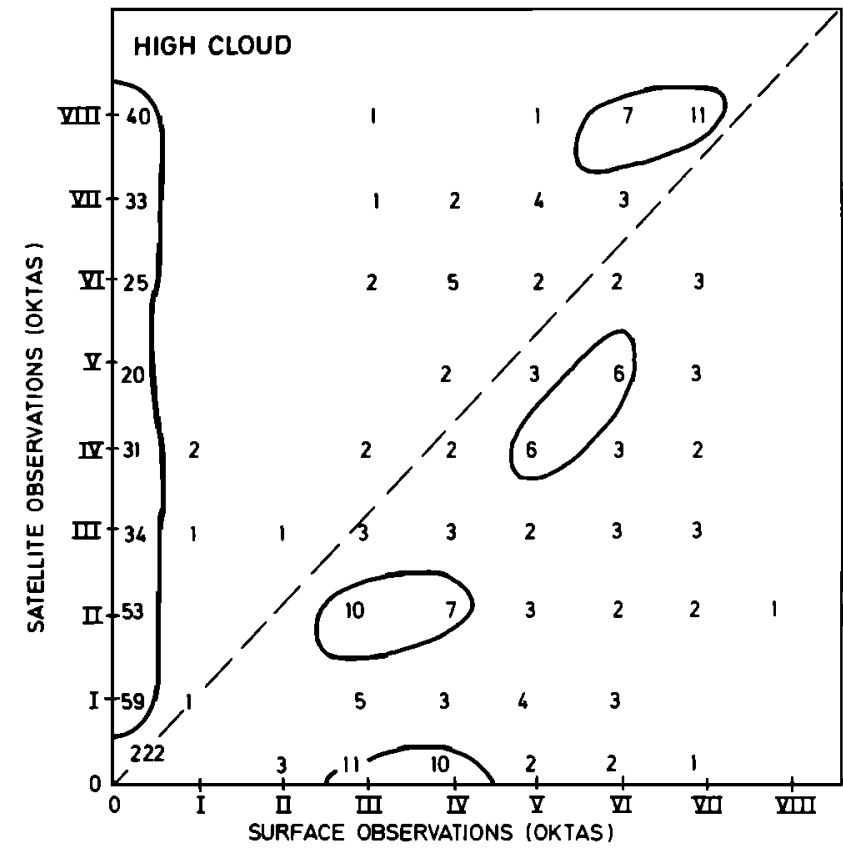

Fig. 2c. As for Figure 2a, but for high cloud and using date from southern Britain only.

each day has been plotted at every surface station to produce 60 maps. The terminology of a positive cloud amount difference being the result of an apparent surface observer overestimate was retained. These maps are very "spotty," suggesting that the general conclusions drawn in section 3.1. may not always be valid.

Considering just the total cloud amount difference maps, region 1 shows the most agreement (i.e., the most zeroes) and most disagreements were of 1 okta. Regions 2 and 4, and, inland, region 3 , tend to have larger disagreements, often of 2 oktas. Region 5 and the coastal part of region 3 show the most disagreement, frequently exhibiting disagreements of 2 oktas or more. Looking at synoptic charte and satellite images for the 20 days, it can be seen that, overall, region 1 is the most cloud-free and region 5 is the most cloudy. However subareas of regions exhibit a wide range of "agreement," and whole regions can differ from the generalised outline above on individual days.

The maps of low- and high-cloud amount differences appear similarly spotty. Often the occurrence of negative and positive differences was approximately equal in both frequency and magnitude (e.g., Figure 6; August 5). On this day the satellite and surface observers agree that there is little or no high cloud, giving rise to the zeroes in Figure 6c. The 8-okta differences in the low-cloud retrievals in region 4 seem to coincide with the edges of vertically developed clouds. The apparent overestimate by the satellite is related to the retrieval method, which does not allow for partial coverage of individual pixels and can thus confuse pixels partially covered by a particular cloud type with another cloud class.

Region 5 on July 31 (Figure 7) exhibits the clearest example of obscuration of cloud by other layers. The total cloud amounts can be seen to be in almost perfect agreement (Figure 7a), while the surface observer overestimates low-cloud amount (Figure 7b) and the satellite retrieval overestimates high-cloud amount (Figure 7c). In both cases the differences range up to 8 oktas.

Two particularly interesting days are the July 30 and the 


\section{TOTAL CLOUD}

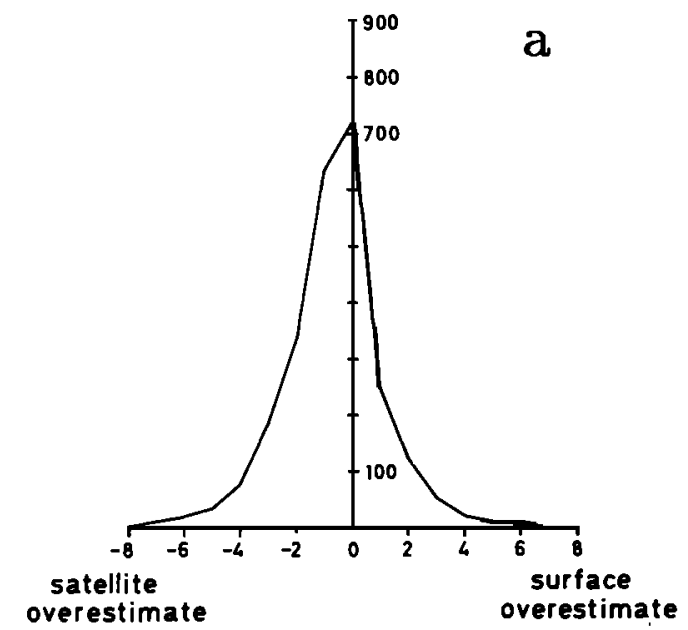

(surface underestimate)

( satellite underestimate)

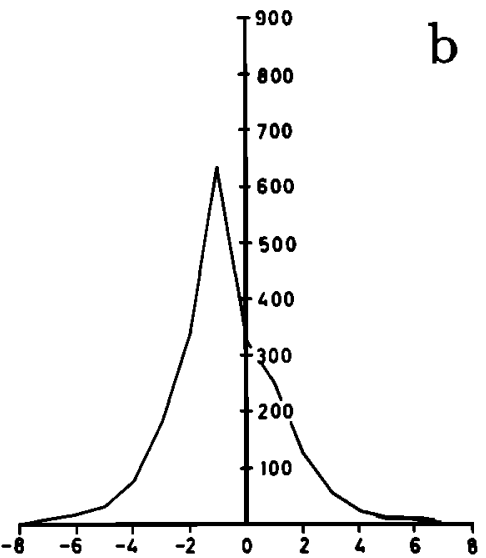

satellite

overestimate

(surface underestimate) surface

( satellite underestimate) overestimate

Fig. 3. (a) Frequency distribution of the difference of total cloud amount in oktas between the ourface observer and satellite retrieval for the 124 stations orer the 20 days. (Positive values occur when ourface values are greater than eatellite retrievals.) (b) As for Figure 3a, except agreement in totally clear and totally cloudy skies hes been removed from the zerodifference column. (Ponltive values occur when surface values are greater than satellite retrievals.)

August 10, 1983. July 30 was one of the hottest days on record for France and is correspondingly the most cloud free of all the 20 days in the study. Very good agreement is seen in both the total and low-cloud amount difference maps. There are a large number of zeroes, not just in region 1 but in regions 2 and 4 as well. On August 10 a subjective analysis of the visible and infrared photographs shows the east of Fingland and the Welsh borders to be covered by low cloud or fog but the rest of England and Wales to be cloud free. On this day there was a high-pressure area stationary off the northeast coast of Britain, with a ridge extending from Scandinavia to the Asores. There is no evidence to auggest upper level cloud. Ground observers and satellite retrievals agree for most of the stations, finding either clear sky or low clouds. With the exception of the 5- okta difference, which appears to be due to a peculiarity at that particular station, the difference between the two low-cloud retrievals is less than 2 oktas.

For the stations of Wyton, Mumbles Head, Cardiff, and Exeter, detailed results are given in Table 4. The satellite retrieval includes cloud layers other than low clouds. An investigation of the retrieval for these particular stations shows that extreme edges of low clouds have sometimes been classified as higher semitransparent clouds and that some groups of pixels around coastlines, showing high variances, have been classified as partial coverage with medium clouds.

On July 28 and 29, region 5 exhibits large surface observer overestimates in the total cloud amount difference maps. On the July 29, 13 of the 32 stations show a surface observer overestimate of 4 oktas or more (Figure $8 a$ ). The

\section{LOW CLOUD}

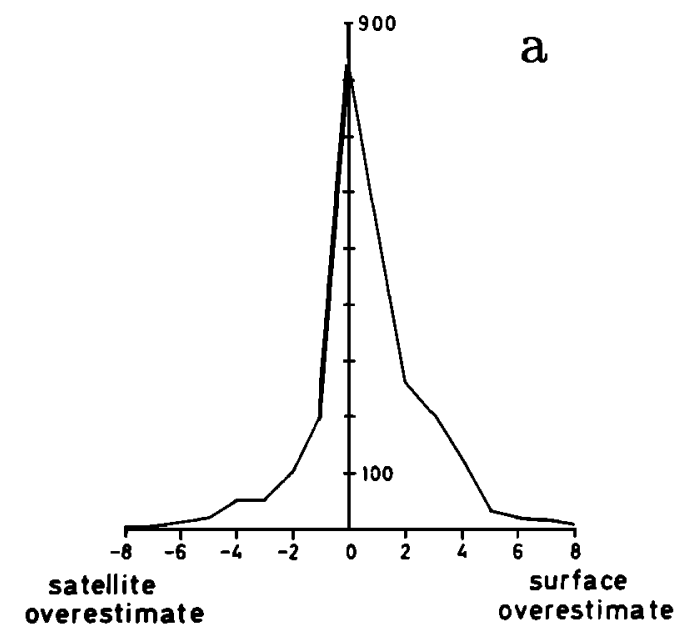

(surface underestimate)

(satellite underestimate)

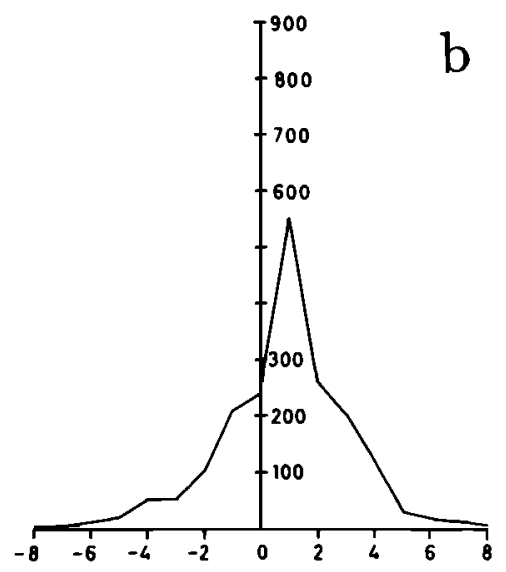

satellite

overestimate

(surface underestimate)

surface

overestimate

(satellite underestimate)

Fig. 4. (a) Frequency distribution of the difference of lowcloud amount in oltas between the surface observer and eatellite retrieval for the 124 atetions orer the 20 days. (Positive values occur when eurface values are greater than gatellite retrievals.) (b) As for Figure 4a, except agreement in totally clear and totally cloudy akies has been removed from the zerodifference column. (Positive values occur when aurface values are greater than satellite retrievals.) 
TABLE 3. Number of Occurrences of okta Differences" for the Types of Cloud Studied

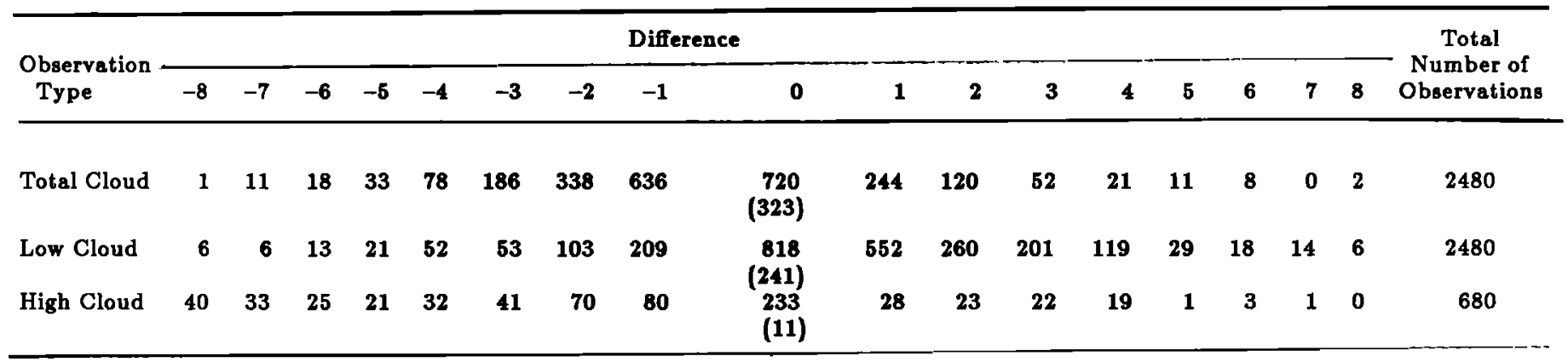

*Difference is stated in oktas.

Number in parentheses is the number of occurrences of total, low- or high-cloud differences of zero oktas which were not due to clear or totally overcast conditions.

low-cloud amount difference maps (Figure 8b) show surface observer overestimates, however, they are much smaller than in the total cloud amount, typically 1 okta. Moving to the high-cloud amount difference maps, there are large surface observer overestimates, 5 oktas and above on July 28 and 3 oktas and above on July 29 (Figure 8c). Ignoring zero okta cases on July 28, the surface observer reports either 6 or 7 oktas, whereas the satellite never retrieves more than 1 okta. More remarkably, on July 28, only 3 of the 32 surface obgervers report zero oktas high-cloud amount; the rest report 3 - 6 oktas, with one 7-okta report. The satellite-retrieved high-cloud amount at all 32 stations is zero oktas. Subjective analysis of the METEOSAT visible and infrared photos suggests some low clouds covered with a tenuous layer of cirrus.

These preliminary results indicate that when there is no cloud, the surface observer and satellite retrievals agree. On days that were cloudy, particularly when several cloud layers, including cirrus, occurred, the total cloud agreement was reasonable, usually within 2 oktas. In many cases, when the satellite detected a total coverage, the observer reported only 7 oktas. For low cloud, however, the agreement was very poor, with the satellite underestimating by between 2 and 5 oktas. This disagreement seems to be due to upper level cloud obscuring the satellite's view of the low cloud.

\section{Some Posgible Sources of Discrepancies}

The results presented above underline the basic problem inherent in all comparisons between surface and satellite observations: the upward view of the surface observer differs from the downward view of the satellite sensor. Note how the low-cloud amount frequency distribution (Figure 4) shows a skew toward a satellite underestimation due to the low clouds being obscured by high clonds. Similarly, the high-cloud amount frequency distribution (Figure 5) shows a slight skew towards a surface observer underestimation due to the high clouds being obscured by the low clouds.

All the differences are not so simply resolvable. The differences of layer and total cloud estimates (Figures 6, 7, and 8) are extremely "spotty" suggesting a range of mechanisms causing differences. Also, although Barnes [1966] and Malberg [1973] both found that the surface observer tended to overestimate the total amount of cloud compared to the satellite, the results presented here show a tendency for the opposite: for the satellite to overestimate total cloud amount

\section{HIGH CLOUD}

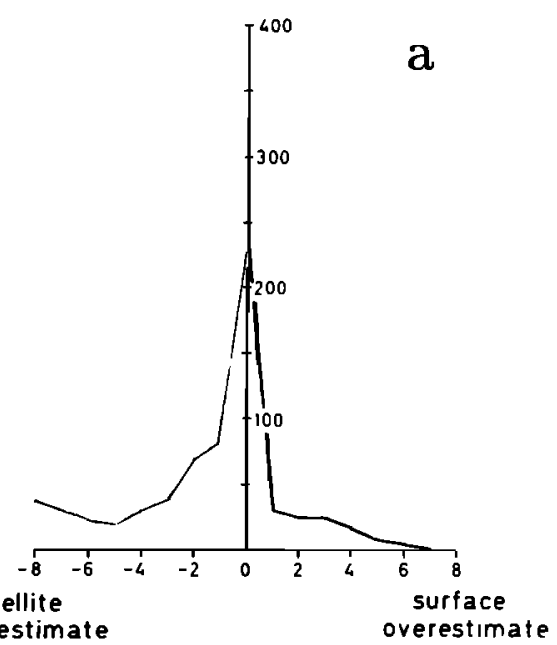

(surface underestimate)

(satellite underestimate)

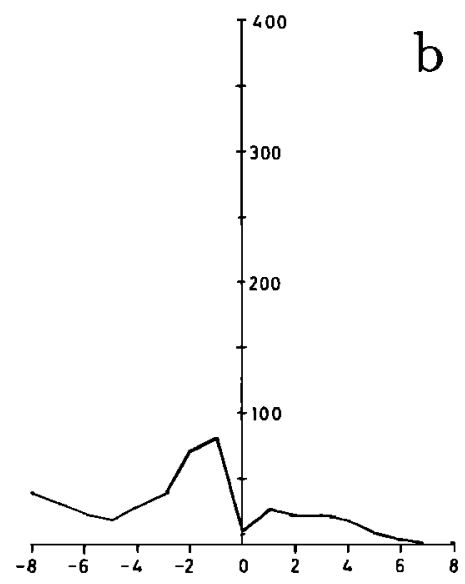

sat ellite

overestimate (surface underestımate) surface

overestimate

(satellite underestimate)
Fig. 5. (a) Frequency distribution of the difference of highcloud amount in oktas between the surface observer and atellite retrieval for the 34 British stations over the 20 days. (Positive values occur when surface values are greater than satellite retrievals.) (b) As for Figure 5a, except agreement in totally clear and totally cloud akies has been removed from the zerodifference column. (Positive values occur when surface values are greater than satellite retrievals.) 

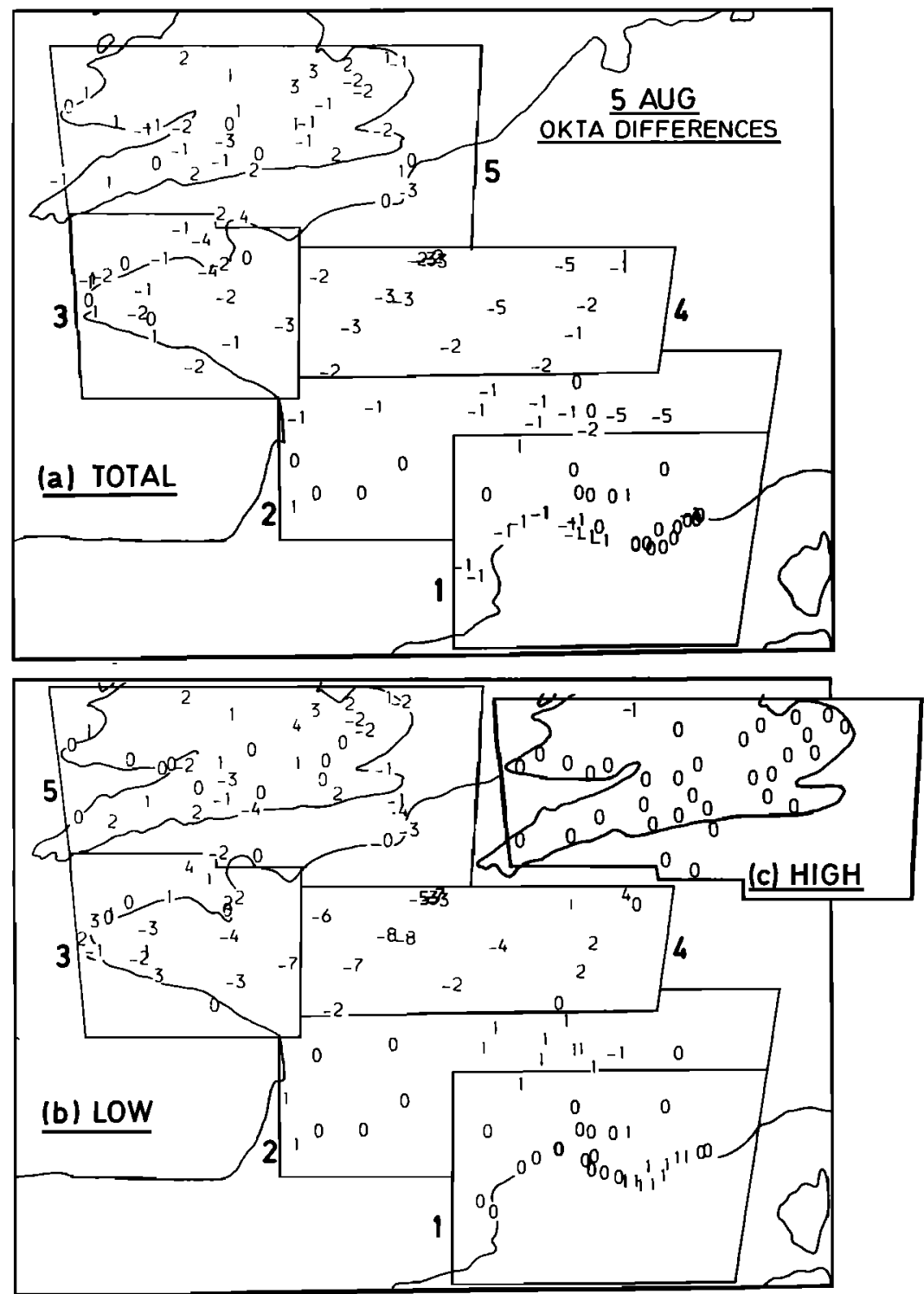

Fig. 6. (a) The difference of total cloud amount in oktas between the surface observer and satellite retrieval for the 124 stations for August 5, 1983. (Positive values occur when surface values are greater than satellite retrievals.) (b) As for Figure 6a, but for low cloud. (c) As for Figure 6a, but for high cloud.

(Figures $2 a$ and $3 b$ ). In the following four subsections some possible causes of the observed discrepancies are examined.

\subsection{Resolution Differences Between Two Kinds of Measurements}

In the satellite retrieval algorithm used here, each pixel, representing an area of about $50 \mathrm{~km}^{2}$, is classified as noncloudy or as covered with a particular class of cloud. For a ground observer, clear and overcast conditions (for different cloud types) are also easily identified for a similar area. This is particularly true if the area is directly above the observer. Observation of a directly overhead area can result in different biases, depending on the true coverage. In the case of few small clouds (very sparse coverage), the satellite will underestimate the coverage by detecting no cloud under a certain threshold of signal on the two radiometric channels. Conversely, over this threshold the satellite will detect a total cloud coverage for the pixel, whereas the observer will report a partial coverage.

Typically, in the case of low fractional coverages, the re- sult of this resolution difference is an underestimation by the satellite and, in the case of high fractional coverages, an overestimation by the satellite. However, this effect is somewhat attenuated by the sampling area of the satellite, which contains typically in this study $15 \times 19=285$ pixels. It remains to be seen if such large areas are also representative of surface observations.

\subsection{Representativeness of Surface Station Observations}

A major problem was selecting the area over which the satellite retrievals were to be made. Clearly, it was necessary to choose an area similar to that viewed by a surface observer. As discussed above, Barrett and Grant [1979] identified a theoretical maximum radius of vision of a surface observer as $50 \mathrm{~km}$, thus suggesting an area of size 100 $\mathrm{km}$ by $100 \mathrm{~km}$ for this comparison. On the other hand, Barnes [1966] pointed out that the optimum method for making such an intercomparison was not obvious because of the very different areas viewed by the satellite and surface observer. Certainly, the area viewed by a surface observer is 

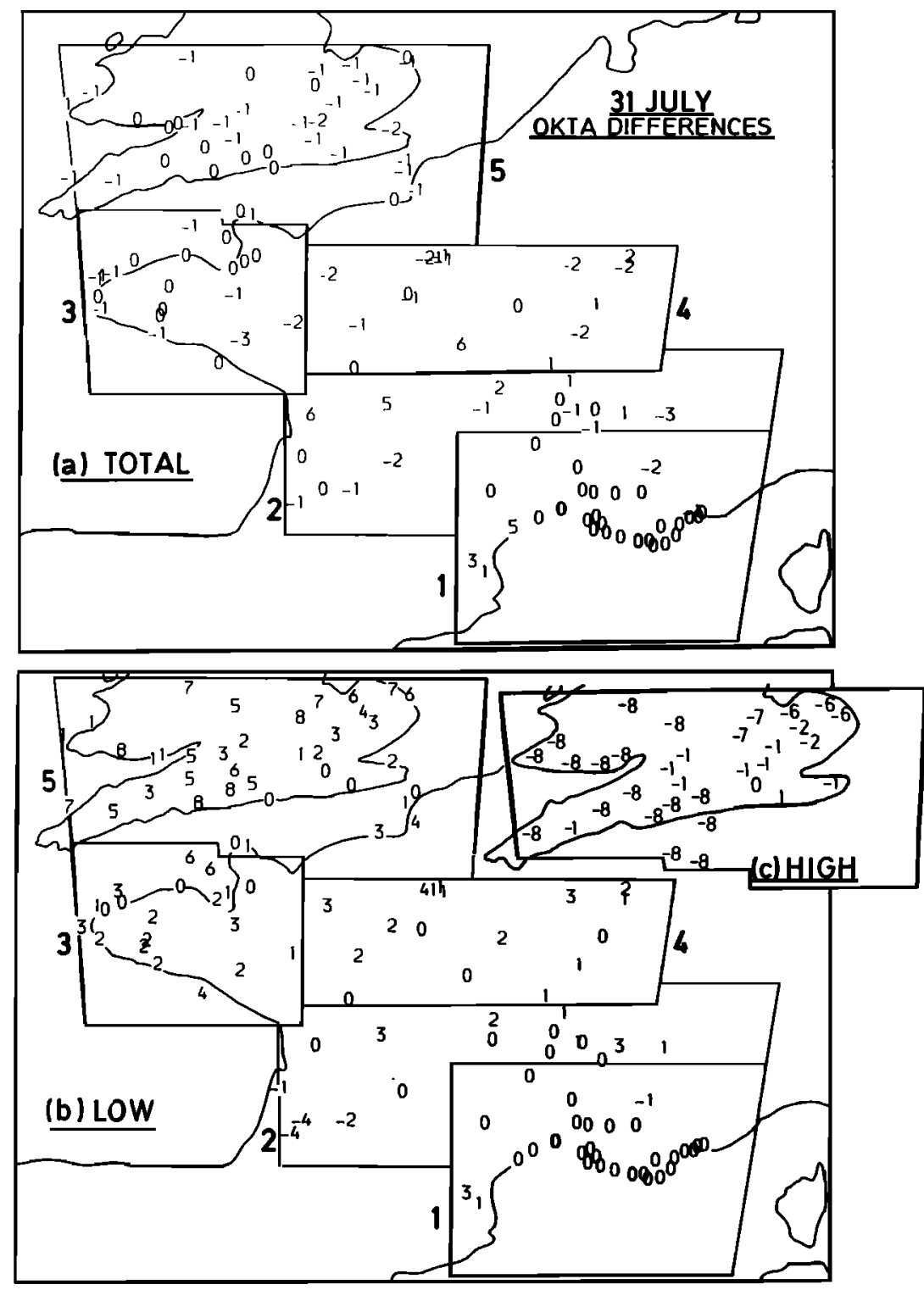

Fig. 7. As for Figure 6, but for July 31, 1983.

determined by the height of the clouds observed, since this determines the "celestial dome" which he views. In a heterogeneous cloud configuration an observer can see further in one direction than another. This problem is compounded by variations in atmospheric transmissivity and the amount of illumination. The problems of perspective and inhomogeneity in area viewed led us to reconsider the choice of area size.

In an attempt to examine the representativeness of singlestation data for an area of $100 \mathrm{~km}$ by $100 \mathrm{~km}$, a study of cloud reports from three surface stations in each of the five regions was undertaken. The stations concerned for each region are given in Table 5 . The stations were chosen for each region on the basis that they were the nearest to each other with the most complete set of data (i.e., avoiding stations for which 9 and -9 codes had been reported). In regions 2 and 3 , stations are within a 100-km radius of each other, in regions 1 and 5 within a 50-km radius, and in region 4 within a $20-\mathrm{km}$ radius. Note that with reference to Figures 6,7 , and 8 , the areas used for the satellite estimations corresponding to these stations generally have many pixels in common: for example, $64 \%$ of the pixels for the three stations of region 4 and $50 \%$ of the pixels for the stations of region 5 , thus reducing large differences in the satellite retrievals for these adjacent surface stations.

Figures 9a-9e are plots of 1200 UT observations for each of the three stations in the five regions for the full period. Generally, it was found, perhaps not surprisingly, that the nearer the stations were together the better the agreement; region 4 having the best overall agreement. Locational differences as well as spatial separation may cause disagreement. Both regions 1 and 3 contain a mixture of inland and coastal stations (see Table 5) and in region $5,50 \mathrm{~km}$ is the difference between the center of London and the Sussex countryside. Even in region 4, which has the smallest radius of station separation, differences of 2 and 3 oktas can often be seen. Greater differences can be seen in other regions. For example, in region 1 on July 31, there is a discrepancy of 5 oktas between Sete and the other two stations. Disagreement between surface observations at nearby stations can be caused by fronts moving across the region, which may result in a time lag in the increase or decrease in cloud amount be- 
TABLE 4. Satellite- and Surface-Retrieved Low-, High-, and Total Cloud Amounts for Four Stations in Region 5 for August 10, 1983.

\begin{tabular}{lcccccc}
\hline Station & $\begin{array}{c}\text { Surface } \\
\text { Low }\end{array}$ & $\begin{array}{c}\text { Satellite } \\
\text { Low }\end{array}$ & $\begin{array}{c}\text { Surface } \\
\text { High }\end{array}$ & $\begin{array}{c}\text { Satellite } \\
\text { High }\end{array}$ & $\begin{array}{c}\text { Surface } \\
\text { Total }\end{array}$ & $\begin{array}{c}\text { Satellite } \\
\text { Total }\end{array}$ \\
\hline Wyton & 4 & 4 & 0 & 0 & 4 & 5 \\
Mumbles Head & 0 & 0 & 0 & 0 & 0 & 1 \\
Cardiff & 1 & 1 & 0 & 0 & 1 & 2 \\
Exeter & 0 & 0 & 0 & 0 & 0 & 1 \\
\hline
\end{tabular}

Cloud amounts are stated in oktas.

tween the stations [Greenwood, 1985]. For example, on July 22 for the five regions, plots of all the available data showed that trends within regions were closely correlated with the movement of a cold front, which passed over Paris around midday. However, this type of synoptic forcing is unlikely to be responsible for all the day-to-day discrepancies seen in Figure 9.

These observations are not sufficient to identify firmly an optimal radius of representativeness of a ground observa- tion of cloud cover; the number of cases studied here being too small to make significant estimations of correlation coefficients as a function of the distance between stations. However, regions 1 and 5, with a 50-km radius around the central location, do show a reasonable consistency, which suggests that the initial choice of an area of size $100 \mathrm{~km}$ by $100 \mathrm{~km}$ was satisfactory within the constraints of time and data availability. It must be noted that the reason for the common 1- to 2-oktas difference between adjacent surface
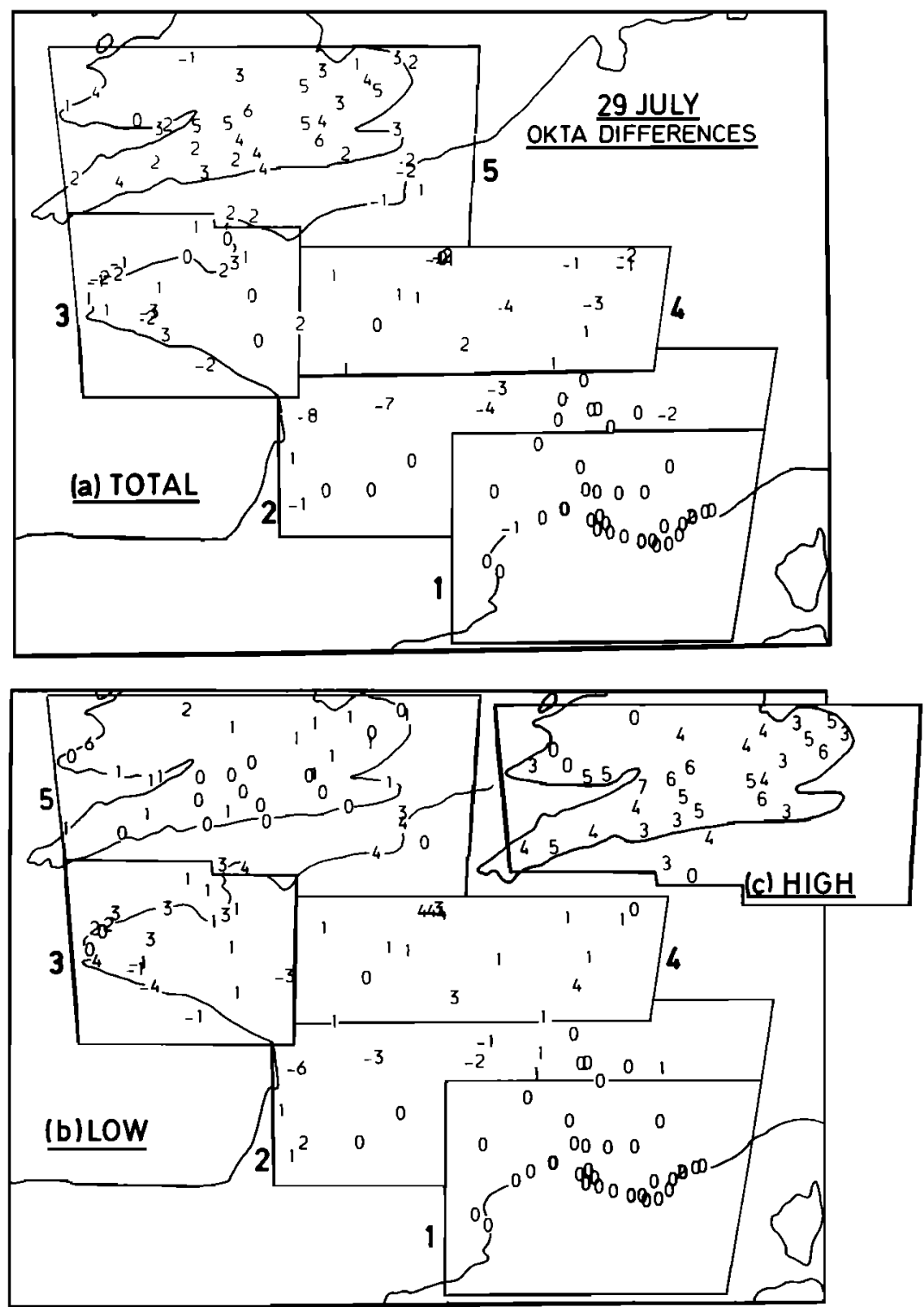

Fig. 8. As for Figure 6, but for July 29, 1983. 
TABLE 5. Stations Used in Each Region to Select the Size of the Satellite Retrieval Aree

\begin{tabular}{|c|c|c|}
\hline Region & Station & Comment \\
\hline 1 & $\begin{array}{l}\text { Montpellier } \\
\text { Sete } \\
\text { Nimes }\end{array}$ & $\begin{array}{l}\text { "Center," inland } \\
\sim 30 \mathrm{~km} \text { southeast of center, coastal } \\
\sim 50 \mathrm{~km} \text { northwest of center, inland }\end{array}$ \\
\hline 2 & $\begin{array}{l}\text { Agen } \\
\text { Gourdon } \\
\text { Mont de Marsan }\end{array}$ & $\begin{array}{l}\text { "Center," inland } \\
\sim 90 \mathrm{~km} \text { northwest of center, inland } \\
\sim 100 \mathrm{~km} \text { southeast of center, inland }\end{array}$ \\
\hline 3 & $\begin{array}{l}\text { Pointe du Grouin } \\
\text { Ile de Brehnt } \\
\text { Rennes }\end{array}$ & $\begin{array}{l}\text { "Center," coastal } \\
\text { a } 90 \mathrm{~km} \text { northeast of center, coastal } \\
\sim 70 \mathrm{~km} \text { southwest of center, inland }\end{array}$ \\
\hline 4 & $\begin{array}{l}\text { Villacoublay } \\
\text { Trappes } \\
\text { Paris Orly }\end{array}$ & $\begin{array}{l}\text { "Center, inland, outskirts of Paris } \\
\sim 15 \text { km eant of center, inland, outskirts of Paris } \\
\sim 20 \mathrm{~km} \text { southwest of center, inland, outskirts of Paris }\end{array}$ \\
\hline 5 & $\begin{array}{l}\text { London W. C. } \\
\text { Heathrow } \\
\text { Gatwick }\end{array}$ & $\begin{array}{l}\text { "Center," inland, central London } \\
\sim 30 \mathrm{~km} \text { east of center, inland, semiurban } \\
\sim 50 \mathrm{~km} \text { south of center, inland }\end{array}$ \\
\hline
\end{tabular}

stations is likely to be a combination of observational uncertainty and dynamic variability in the clouds themselves. These two causes are not readily separable.

\subsection{Angle of View of Satellite and Surface Observers}

It is well known that retrieval of cloud amount from satellites is subject to systematic errors whenever the viewing angle $\psi$, which the satellite subtends at the cloud, is other than zero [e.g., Bunting and Hardy, 1984]. For example, Snow et al. [1985] have used photographs from the Space Shuttle to construct curves which show the increase in satelliteretrieved cloud cover as a function of the viewing angle. Cloud cover, which is $20 \%$ at a viewing angle of $\psi=0^{\circ}$, increases to over $30 \%$ for $\psi=50^{\circ}$.

Undoubtedly, METEOSAT is viewing the sides of cloud at the latitudes $\left(39^{\circ}-53^{\circ} \mathrm{N}\right)$ of importance in this study. Referring to Figure 10, the angle $\psi$, which is the satellite viewing angle from the vertical, is given by

$$
\psi=\theta+\phi
$$

where $\phi$ is the latitude, and for METEOSAT, $\theta$ is given by

$$
\theta=\tan ^{-1}\left\{\frac{R \sin \phi}{H+R \cos \phi}\right\}
$$

For a satellite height $H$ of $36,000 \mathrm{~km}$ and taking the radius of the earth $R=6370 \mathrm{~km}$, gives for the mean latitude of the study area $\left(\phi=46^{\circ}\right), \theta=6.5^{\circ}$ and hence $\psi=51.5^{\circ}$. In the case of region 5 the mean latitude of the region is $\phi=51^{\circ}$, giving $\Theta=7.1^{\circ}$ and $\psi=58.1^{\circ}$. Thus from the example cited above it can be seen that the METEOSAT cloud retrieval is likely to be an overestimate, perhaps by as much as about $10-15 \%$ cloud amount.

On the other hand, consideration is rarely given to the fact that the surface observer also suffers from the problem of cloud sides becoming important in his sky cover estimation when clouds are either vertically developed or near to his horizon. The case of the surface observer is more diffcult to consider, since the "error" in his retrieval depends upon the cloud configuration which he views (i.e., whether the clouds are close to the zenith or have zenith angles close to $90^{\circ}$ ). Merritt [1966] found that experienced observers tended to overestimate the sky cover when clouds were near the horizon, as compared to objective retrievals from all-sky camera photographs, but to underestimate the sky cover for clouds evenly distributed orer the sky. The position of the cloud is important. A cloud overhead will look much larger than one on the horizon as long as it is not highly vertically developed [e.g., Henderson-Sellero et al., 1984]. It is possible, however, to calculate the mean viewing angle of the observer, $\alpha$, as shown in Figure 10, by assuming that the observer has a clear view to his horizon [HMSO, 1969] and then integrating the viewing angle over the hemisphere, namely,

$$
\alpha=\frac{\int_{0}^{\pi / 2} \mu 2 \pi R^{2} \sin \mu d \mu}{\int_{0}^{\pi / 2} 2 \pi R^{2} \sin \mu d \mu}
$$

On evaluation, it is found that $\alpha=57.3^{\circ}$.

Thus excluding any considerations of atmospheric scatter and absorption and assuming that a spatially homogeneous cloud field is viewed by both the satellite and the surface observer, it appears that at a latitude of $50.3^{\circ}$ the induced errors due to observation of cloud sides as well as the upper or lower cloud faces are equivalent for METEOSAT and a surface observer. This latitude lies in the region studied here, in fact, just north of the southern boundary of region 5 (see Table 2).

These calculations do not, of course, demonstrate that there will be no errors induced in the comparison between satellite and surface retrievals of cloud amount due to the viewing of cloud sides. However, to first order, it does seem that the level of cloud amount overestimation will be similar for both satellite retrieval and surface observers. We therefore conclude tentatively that this problem is not likely to be responsible for the differences described in the preceding sections.

\subsection{Observing Practices and Bias}

Another possible cause of differences between the satellite and the surface retrievals of cloud amount is the ability (or lack of it) to resolve gaps between a broken cloud field. 

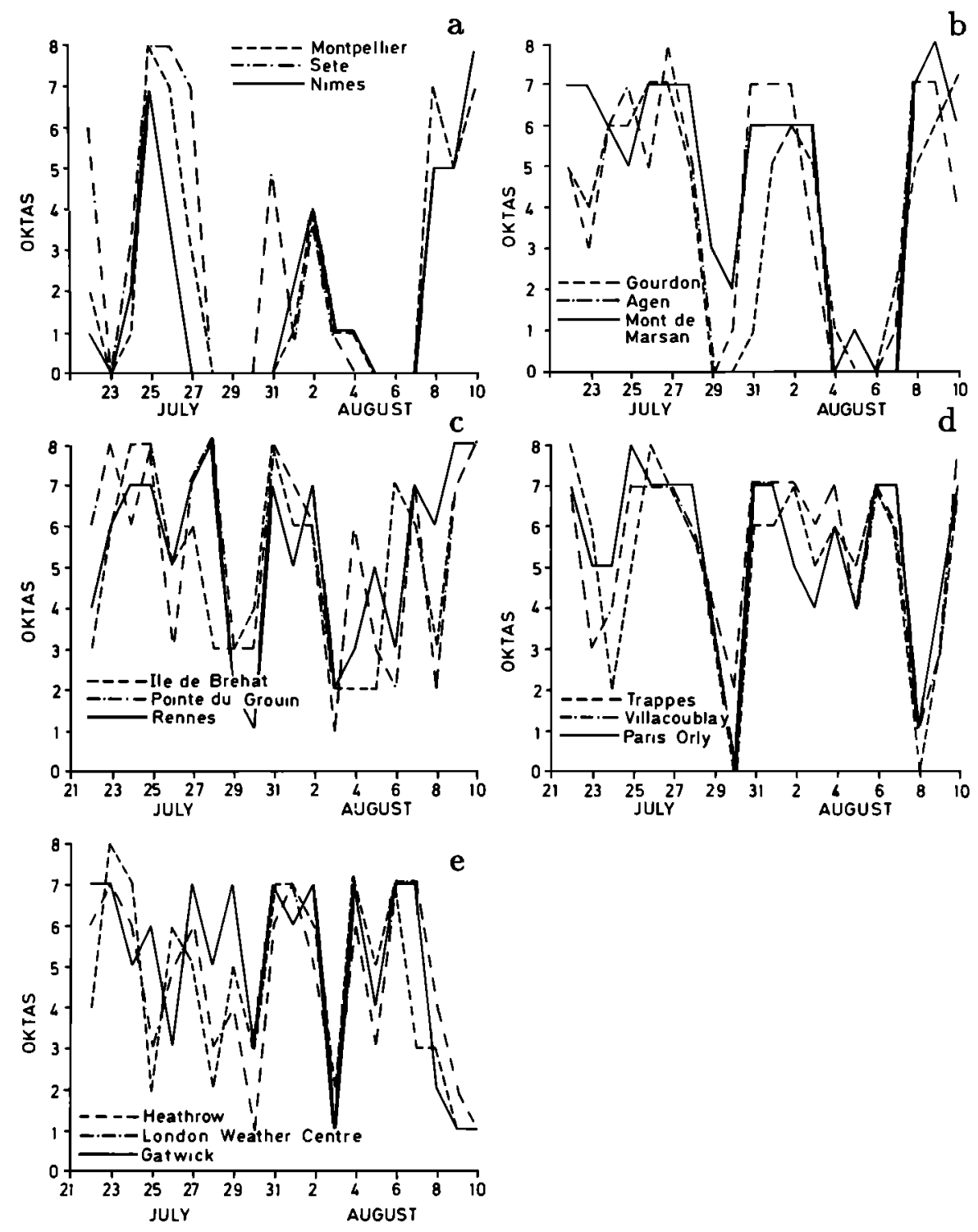

Fig. 9. Observations of total cloud amount at 1200 UT for the period July 22 to August 10, 1983, taken from the flve sets of three stations listed in Table 3. (a) Region 1. (b) Region 2. (c) Region 3. (d) Region 4. (e) Region 5.

At large viewing angles ( $\psi$ and $\alpha$ in Figure 10) both satellite and surface observers are unable to recognise spaces between clouds and thus overestimate cloud amount [Malberg, 1973]. This problem is made worse for the satellite retrievals by the relative coarseness of the pixel resolution ( $6 \mathrm{~km})$. Thus on first inspection it seems possible that the satellite view of gaps between clouds is more likely to be obscured than the view of the surface observer. It can be seen in Figure 11, which compares the frequency of retrieval of total, low-, and high-cloud amounts in oktas by the surface observers and the satellite in this study, that the most frequent total cloud amount reported by the surface observers is 7 oktas; while the most frequent cloud amount retrieved from the satellite data is 8 oktas. This apparent overestimate of cloud amount in any nearly overcast situation by the satellite does seem to support the hypothesis that the satellite retrieval is unable to differentiate gaps in a broken cloud deck. However, after studying surface observational practice, it seems likely that there is a bias in the surface retrievals which is caused by an instruction to surface observers. At least in the United
Kingdom, surface observers are instructed to report 7 not 8 oktas of cloud cover if they have reason to believe that there are gaps in the cloud deck they observe, even if these gaps are not visible to them at their observing location (A. Kite, private communication, 1984).

There are also biases in surface-retrieved cloud amounts which owe more to the psychology of observation than to the training of the observers. For example, the low-cloud distribution in Figure 11a suggests that the surface observers "prefer" reports of 1,3 , and 7 oktas of low-cloud amount, as compared with the satellite retrievals. That the same preference is not exhibited in the high-cloud frequency distributions (Figure 11) could be due to the incomplete reporting of high-cloud amounts, as described in section 2. Indeed, the implications of reporting criteria $1-4$, listed in section 2.2., are rather hard to understand. It seems very likely that small amounts of high cloud could be observed but not reported as a result of these criteria. Despite this our results have shown that surface observations of high cloud generally agree with visual image interpretation, and often the 

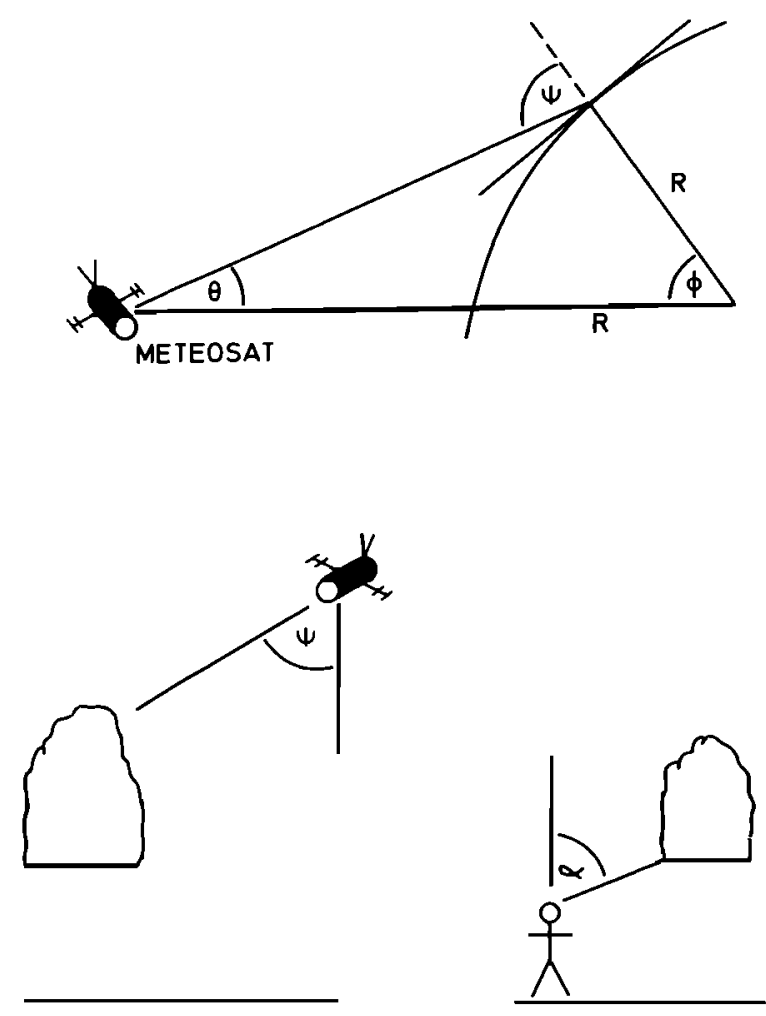

Fig. 10. Schematic diagram showing satellite- and surfaceviewing angles of a generalized cloud.

detection skill is better than that of the satellite retrieval algorithm (e.g., Figure 8c).

\section{Discussion}

\subsection{Total Cloud Amount Comparions: A "Validation"?}

The area over which this comparison was undertaken is relatively small and suffers (or enjoys) rapidly changing weather. Thus it is almost impossible, and certainly unwise, to make statements about the level of agreement between surface and satellite observations in general, based upon the results described here. However, some locationally and, perhaps, seasonally specific conclusions can be drawn. As far as total cloud amount is concerned, surface observations and satellite retrievals will agree most closely when there is no cloud, when the area is completely cloud covered, or when only one cloud layer is present.

Overall, 64\% of the comparisons of total cloud amount agreed to within \pm 1 okta and $83 \%$ agreed to within \pm 2 oktas (Table 3). This level of agreement (or difference) is similar to that found among a wide range of satellite-based retrieval algorithms by Rossow et al. [1985]. Rossow et al. find (see their Figure 2 and Table 2) very good agreement for clear and total overcasts and a range of $\pm 10 \%-15 \%$ (about \pm 1 okta) for intermediate cloud amounts. This suggests that surface observations would show roughly the same relationship with satellite retrievals made using other algorithms. Moreover, since selected surface stations in areas of $100 \mathrm{~km}$ by $100 \mathrm{~km}$ exhibit differences which are up to 2 oktas, the level of agreement achieved might have been considered encouraging had this been a "validation" exercise. The success is limited by uncertainty, however. If the differences among surface stations were solely because of uncertainties in the surface observation technique, then the general satellite versus surface differences are "good." On the other hand, the result is less reassuring if the discrepancies among the surface observers were due to spatial variations in the cloud field. The available data do not permit identification of the "true" cloud characteristics but, since the objective of this study was to examine whether surface observations of clouds could be used to improve satellite retrievals, the question need not be considered in detail.

In the case of total cloud amount, it has been shown that in some cases totally cloudy and totally cloud-free satellite retrievals can be enhanced following comparison with surface observations, which may show breaks in the cloud deck or clouds smaller than those resolvable from the satellite data. Surface observations are also extremely useful for identification of thin cirrus (see below).

\subsection{Low Cloud Amount: Contamination Near Coasts}

For low-cloud amounts the best agreement is found when only low cloud exists. There were slightly fewer agreements within 2 oktas (78\%), and for specific dates and locations,

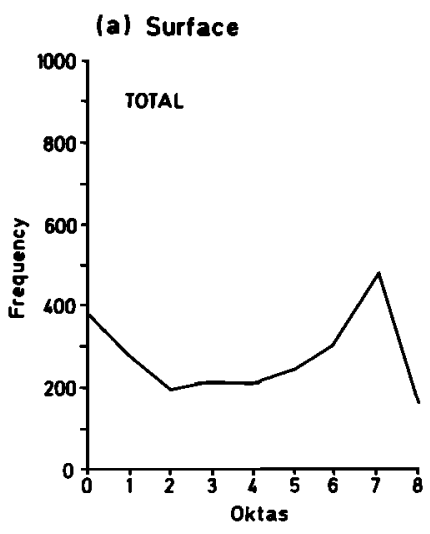

(b) Satellite
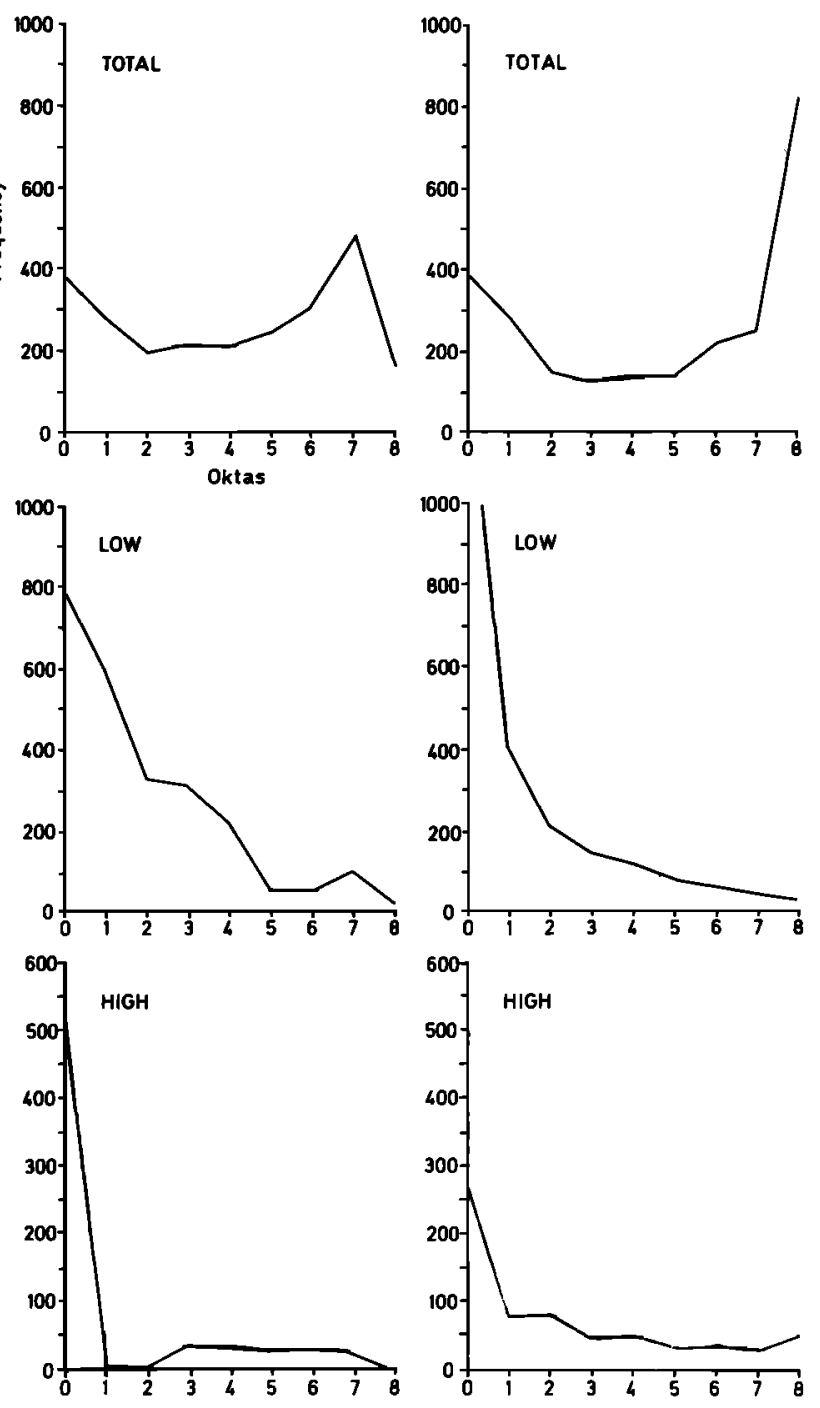

Fig. 11. (a) Surface observations: frequency of occurrence of okte values for total cloud, low cloud and high cloud. (b) As for Figure 11a, but from satellite retrievals in this study. 
TABLE 6. Total Cloud Cover Detected by Surface Observer and Satellite Retrieval in Three Different Cases of High Cloud Detection

\begin{tabular}{lccc}
\hline & $\begin{array}{c}\text { No High Clouds } \\
\text { Detected by } \\
\text { Surface Observer }\end{array}$ & $\begin{array}{c}\text { High Clouds } \\
\text { Detected by } \\
\text { Surface Observer }\end{array}$ & $\begin{array}{c}\text { More High Clouds } \\
\text { Detected by Surface } \\
\text { Observer than by } \\
\text { Satellite }\end{array}$ \\
\hline $\begin{array}{c}\text { Total cloud cover } \\
\text { retrieved by ourface } \\
\text { observer }\end{array}$ & 5.3 & 5.0 & 5.0 \\
$\begin{array}{c}\text { Total cloud cover } \\
\text { retrieved by satellite }\end{array}$ & 6.3 & 4.6 & 3.3 \\
\hline
\end{tabular}

Cloud cover is stated in oktas.

disagreement is considerable. Wherever higher cloud overlies the low cloud there is a large difference (up to 8 oktas; e.g., Figure 7) between surface and satellite retrievals; the satellite retrieval is found to be underestimating the lowcloud amount.

There is a problem associated with cloud retrieval near coasts. This could be solved in part by building separate learning sets for land and ocean pixels, but for immediate coastal locations, difficulties remain. This was illustrated here by the case of August 10 (Table 4), when clusters other than low cloud were identified primarily because of the nearcoastal location of the station. One solution to this difficulty is that locations where the number of coastal pixels is high should be removed from satellite retrievals whenever surface observations can replace the satellite retrieval.

\subsection{The Problem of High-Cloud Retrieval}

The problem of cirrus cloud retrieval is, perhaps, one of the most perplexing problems facing users of automatic satellite retrieval algorithms. Thin cirrus with varying emissivity can be particularly troublesome when threshold techniques are applied [Rossow et al., 1985]. The clustering technique used in this study to retrieve cloud amounts seems to do fairly well in retrieving high-cloud amount in most cases. However, in other cases, like July 29, 1983, large discrepancies can occur (see Figure 8c). There are several possible explanations. In addition to the problems already mentioned in the previous sections (high cloud obscured by other layers for the ground observer), one problem is inherent in attributing the cloud classes found by the clustering technique to particular cloud layers. In the case of the classification over region 5 , for example, 10 classes were found, four of them representing undoubtedly more or less thick high-level clouds (in the satellite sense, that is, with a high upper surface). Another class could represent either very thin cirrus, or thin middle-level clouds. In the results presented here this class was attributed either to high clouds or to middle-level clouds, according to its environment: middle-level clouds when there were more than $5 \%$ of other middle-level clouds, high cloud elsewhere. The conditional addition of this class to the four other classes increases significantly the number of cases where high cloud is detected by the satellite for a particular station (from 286 cases to 428 ).

It can thus be seen that the way of attributing classes to levels has an influence on the comparison, but the correspondence between ground and satellite observations cannot be reached by tuning the class selection: such tuning can be done only on marginal classes of thin clouds or partial coverages.
Other more important factors can play a role in the discrepancies: this is shown by a short comparison of the different cases of high-cloud detection. In the present comparison over region 5 , the observer detected high clouds in $24 \%$ of the cases and the satellite detected high clouds in $63 \%$ of the cases, among which $49 \%$ are thick clouds and $14 \%$ are very thin ones. The proportion of thick and thin high clouds detected by the satellite is correlated with the occurrence of a high-cloud report by the surface observer. If high clouds are detected from the ground, the satellite gives $70 \%$ thick clouds and $30 \%$ thin clouds; if high clouds are not detected by the surface observer, the satellite gives $82 \%$ thick and $18 \%$ thin clouds. This can be related again to the problem of obscuration of the layers: the proportion of thin high clouds detected by the satellite is greater when high clouds are detected by the surface observer, who observes mainly this kind of high clouds that occurs when lower layers are clear or partially covered. Table 6 lists the total cloud cover which is detected by both the satellite and surface observers in these different cases. In the three situations listed, the total cloud cover observed from the ground remains almost the same, whereas it is much smaller for the satellite when the observer detects more high clouds. This underlines again the problem of high clouds hidden to the observer in the case of thick cloud cover or multi- layered clouds, but it emphasizes also that in relatively clear skies the satellite is sometimes unable to detect thin cirrus which are seen by the observer: there are 30 cases where the observer, but not the satellite, detects high clouds; for 15 of these cases, no cloud at all is detected by the satellite. These positive identifications of thin cirrus cloud could be exploited.

\subsection{Summary}

This study has illustrated an obvious truism: that satellite retrieval techniques underestimate low-cloud amount when there is more than one cloud layer and that in this case, ground observers underestimate high-cloud amount. Thus "validation" of layer cloud amounts is impossible for all multilayered situations. Total cloud amounts compared here agreed to about the same degree as adjacent surface observers (see section 4.2.) and slightly less well than different satellite-based retrieval algorithms [Rossow et al., 1985]. This too is a predictable result, restating the fact that most methods of cloud identification and reporting do fairly well most of the time. This conclusion was emphasized by Rossow et al. [1985, p. 884], “a substantial proportion of the total cloud cover is properly detected ... because the clouds are large scale and high contrast in both the visible and infrared ...." 
The objective of this study was to consider whether surface observations offer information of use to ISCCP. At least three affirmative responses have been found:

1. Thin cirrus is correctly identified by surface observers in several cases when satellite retrievals fail to detect its occurrence.

2. Surface observers detect and report small gaps in clond decks and small clouds, both of which are missed by satellite retrievals.

3. Surface observers are not confused by near-coast locations; their cloud observations are much less prone to error than those from satellite retrievals.

Exploitation of these positive results is not straightforward. Since the knowledge of both high- and low-cloud amount is of primary importance for a complete global cloud climatology, since their effects on the radiative fluxes at the top and bottom of the atmosphere are fundamental and since, at the present time, no satellite retrieval technique can infer the level of the "cloud base," one proposal might be to insert surface observations of low-cloud characteristics whenever available. The impact of such action can now be studied: the U.S. Air Force's current, real-time nephanalysis (RT Neph.) includes a data source flag, hence permitting an examination of the impact on spatial homogeneity of the addition of surface reports. We intend to undertake such a preliminary analysis, but we draw attention to the fact that the ISCCP cloud retrievals are already rendered both spatially and temporally heterogeneous by the diurnal variation of the spectral radiance data and by the use of correlative data. We intend to examine a number of approaches: for example, it could be useful to produce and use climatologies, such as that of Hahn et al. [1984], giving the probability of the presence of such cloud types when another type is present but taking as reference the cloud type detected by the satellite. Similarly, the effect of degrading the spatial resolution of the radiance data to be used in the ISCCP retrievals could be examined by comparison with surface observations as well as by intercomparison of satellite-based algorithms. For these and a wide range of other reasons, it seems important to study eystematically the nature of cloud detection by surface observers for specific types and examples of satellite cloud retrievals.

Acknowledgments. One of us (F.D.) wishes to acknowledge sponsorship from the United State Air Force under grant AFOSR-85-0118. The U.S. Government is authorized to reproduce and distribute reprinte for Governmentel purposes notwithstanding any copyright notation thereon. We are very grateful to Julius London and an anonymous colleague for most helpful reviews.

\section{References}

Barnes, J. C., Note on the use of satellite observations to determine average cloudiness over a region, $J$. Geophys. Res., 71, 6137-6140, 1966.

Barrett, E. C., and C. K. Grant, Relations between frequency distributions of cloud over the United Kingdom based on conventional observations and imagery from Landsat 2, Weather, \$4, 416-424, 1979.

Bunting, J. T., and K. R. Hardy, Cloud identification and characterization from satellites, in Satellite Sensing of a Cloudy Atmosphere, edited by A. Henderson-Sellers, pp. 203-240, Taylor and Francis, London, 1984.

Desbois, M., and G. Sèze, Use of time sampling to obtain reliable satellite cloud statistics on limited regions, pa- per presented at International Association for Meteorology and Atmospheric Physics Symposium of International Union of Geodesy and Geophysics, Hamburg, Aug. 1983.

Desbois, M., and G. Sèze, Application of a clustering method for cloud cover analysis over tropical regions, paper presented at Workshop on Cloud Cover and Radiative Fluxes in Large-Scale Numerical Models, European Centre for Medium Range Weather Forecasting, Reading, England, Nov. 1984.

Desbois, M., G. Sèze, and G. Szejwach, Automatic classification of clouds on METEOSAT imagery: Application to high-level clouds, J. Appl. Meteorol., 21, 401-412, 1982.

Fye, F. K., The AFGWC Automated Cloud Analysis Model, AFGWC TM-78-002, 97 pp., HQ Air Force Global Weather Central, Nebraska, 1978.

Global Atmospheric Research Program, Joint Organizing Committee, Study Conference on Parameterization of Extended Cloudiness and Radiation for Climate Models, $\mathrm{Ox}$ ford, England, report, 37 pp., GARP Clim. Dyn. Subprogramme, World Meteorol. Organ., Geneva, Switzerland, 1978.

Greenwood, P., Comparison of surface and satellite cloud evaluation over the United Kingdom, B.Sc. dissertation, Dept. of Geog., Univ. of Liverpool, England, 1985.

Hahn, C. J., S. G. Warren, J. London, R. H. Chervin, and R. Jenne, Atlas of simultaneous occurrence of different cloud types over land, NCAR Tech Note NCAR/TN-241+STR, 21 pp. and 188 maps, Natl. Cent. for Atmos. Res., Boulder, Colo., 1984.

Henderson-Sellers, A., F. Drake, and N. A. Hughes, We've looked at clouds from all sides now, in Satellite Remote Sensing Review and Preview, Proceedings of the Tenth Anniversary International Conference, pp. 255-264, Remote Sensing Society, Reading, England, 1984.

Her Majesty's Stationery Office, Observers Handbook, 221 pp., London, 1969.

Hughes, N. A., and A. Henderson-Sellers, Global 3Dnephanalysis of total cloud amount: Climatology for 1979, J. Clim. Appl. Meteorol., 24, 669-686, 1985.

Malberg, H., Comparison of mean cloud cover obtained by satellite photographs and ground-based observations over Europe and the Atlantic, Mon. Weather Rev., 101, 893897, 1973.

Merritt, E. S., On the reliability and representativeness of sky cover observation, J. Appl. Meteorol., 5, 369, 1966.

Rossow, W. B.,et al., ISCCP cloud algorithm intercomparison, J. Clim. Appl. Meteorol., 24, 877-903, 1985.

Schiffer, R. A., The International Satellite Cloud Climatology Project (ISCCP), preliminary implementation plan, Publ. WCP-20, 77 pp., World Meteorol. Organ., Geneva, 1982.

Schiffer, R. A., and W. B. Rossow, The International Satellite Cloud Climatology Project (ISCCP), the first project of the World Climate Research Program, Bull. Am. Meteorol. Soc., 64, 779-784, 1983.

Schiffer, R. A., and W. B. Rossow, ISCCP global radiance data set: A new resource for climate research, $B$ ull. $A$ m. Meteorol. Soc., 66, 1498-1505, 1985.

Sèze, G., and M. Desbois, Cloud cover analysis on satellite imagery using spatial and temporal characteristics of the data, J. Clim. Appl. Meteorol., in press, 1986.

Snow, J. W., J. T. Bunting, R. P. d'Entremont, D. D. Grantham, K. R. Hardy, and E. M. Tomlinson, Space shuttle cloud photographs assist in correcting meteorological satellite data, EOS Trans. AGU, 66, 489-490, 1985.

F. Drake and A. Henderson-Sellers, Department of Geography, University of Liverpool, P.O. Box 147, Liverpool, L69 3BX England.

M. Desbois and G. Słze, Laboratoire de Météorologie Dynamique, Centre National de la Recherche Scientifique, Ecole Polytechnique, 91128, Palaiseau, Cedex France.

(Received December 30, 1985; revised June 16, 1986; accepted June 24, 1986.) 